Original

\title{
Development of a Japanese version of the Oral Impacts on Daily Performance (OIDP) scale: a pilot study
}

\author{
Mariko Naito ${ }^{1)}$, Yoshimi Suzukamo ${ }^{2)}$, Hiro-O Ito ${ }^{3)}$ and Takeo Nakayama ${ }^{4)}$ \\ ${ }^{1)}$ Department of Preventive Medicine/Biostatistics and Medical Decision Making, \\ Nagoya University Graduate School of Medicine, Nagoya, Japan \\ ${ }^{2)}$ Department of Physical Medicine and Rehabilitation, Tohoku University Graduate School of Medicine, \\ Sendai, Japan \\ ${ }^{3)}$ Department of Preventive Dentistry, University of Tokushima Institute of Health Biosciences, \\ Tokushima, Japan \\ ${ }^{4)}$ Department of Health Informatics, Kyoto University School of Public Health, Kyoto, Japan
}

(Received 20 March and accepted 26 September 2007)

\begin{abstract}
The Oral Impacts on Daily Performance (OIDP) is a well-known oral health-related QOL instrument used internationally. The aim of this study was to develop and test a Japanese version of the OIDP for use in interviews. Following an internationally established method, the OIDP scale was translated using standardized methodology that consisted of forward translation, pilot study and backward translation. A pilot study was carried out using the revised version with 47 local residents (range, 40-105 years). In the item analysis of this study, there were no missing values or ambiguous responses. Twenty-eight percent of the participants replied that they 'had discomfort caused by an oral health problem' in the 'eating' items. Cronbach's alpha coefficient was 0.77 , indicating the internal consistency reliability of the questionnaire. Denture wearers had significantly higher OIDP scores in covariance analysis with age and sex as adjustment factors $(P<\mathbf{0 . 0 5})$. Based on the results, the questionnaire was re-evaluated. A back translation was produced and approved by the original author. Further assessment and validation of this scale is needed in a study with larger sample size. (J. Oral Sci.
\end{abstract}

Correspondence to Dr. Mariko Naito, Department of Preventive Medicine/Biostatistics and Medical Decision Making, Nagoya University Graduate School of Medicine, 65 Tsurumai-cho, Showa-ku, Nagoya 466-8550, Japan

Tel: +81-52-744-2132

Fax: +81-52-744-2971

E-mail: mnaito@med.nagoya-u.ac.jp
49, 259-264, 2007)

Keywords: quality of life; questionnaires; oral health.

\section{Introduction}

Quality of life (QOL) has been related to the degree to which an individual is able to enjoy the significant possibilities of life (1). Oral health conditions have an impact on QOL because they can affect the physical and psychological wellbeing of an individual (2). Since the 1990s, QOL scales that are specific to oral health have been developed in conjunction with numerous QOL studies in the field of oral health care. The Oral Health Impact Profile (OHIP) (3), General Oral Health Assessment Index (GOHAI) (4), and Oral Impacts on Daily Performance (OIDP) (5) are representative QOL scales related to oral health. Many studies have been conducted using these scales, including translated versions, in a number of countries (6-8). Japanese versions of the OHIP and GOHAI have been developed (9-11) and used primarily in areas of occupational health and regional health care (12). However, a Japanese version of the OIDP has not been developed yet.

The OIDP was created based on the concepts of the WHO's International Classification of Impairments, Disabilities, and Handicaps (13). Three versions of the OIDP have been developed and translated into several languages, including an interview and self-administered questionnaire for adults, and a separate one for children 
(14-19). The interview and self-administered questionnaire both assess the degree to which oral health problems have affected the life of the participant over the previous 6 months. The OIDP measures this by scoring the frequency or continuous occurrence of problems that have affected common daily activities during the past 6 months, and it evaluates the participant by calculating a total score (OIDP score). According to this scale, a higher score indicates a lower QOL. The OIDP determines whether an oral problem exists and evaluates the severity and degree to which the life of the patient has been deleteriously affected by the problem.

In recent years, the QOL scale has more often been used to study need assessments and plan oral health services (20-24). In this context, it is anticipated that increasing the available options for QOL scales will contribute to further development of QOL research in Japan. Thus, we focused on the OIDP as an oral health-related QOL scale and sought to develop a Japanese version of the OIDP.

\section{Materials and Methods}

We developed a Japanese version of the OIDP in accordance with internationally established psychometric methods (25). Having obtained permission from the original author to develop a Japanese version, two translators worked separately to transcribe the OIDP scale from English into Japanese.

The 10-item OIDP questionnaire focused on the impact of oral health on the performance of daily activities, such as eating, speaking, cleaning teeth or dentures, undertaking light physical activities, going out, sleeping, relaxing, smiling, enjoying contact with other people, and emotional stability. The frequency and severity of each reported oral health impact were then further assessed. Finally, each impact was attributed to a specific oral condition, as indicated by the respondents. The OIDP score is expressed as the sum of the different performance scores (performance score $=$ severity score $\times$ frequency score) divided by the maximum possible score, and then multiplied by 100 to provide a percentage score. Both frequency and severity scores were expressed on a scale from 0 to 5 . Severity was assessed at six levels, from no effect to very severe effects on everyday life.

The translations were compared by a focus group consisting of translators and specialists in public health and psychometrics. After discussing discrepancies between the two translations with the focus group, we generated a preliminary version of the Japanese-language OIDP scale. We then implemented a pilot study with the preliminary version, with local residents as subjects. Subjects completed the OIDP questionnaire in face-to-face interviews, all of which were conducted by a single interviewer. Items relevant to the scale were analyzed based on the results of the pilot study, and data deficiencies and response patterns were examined and verified.

The concurrent validity was checked by correlation analysis using SPSS (version 10.1). We determined that the criteria for concurrent validity would be satisfied if the correlation coefficient between each item and the related domain score was higher than 0.4 (25). To ensure internal consistency and reliability, we calculated Cronbach's alpha coefficient (26). Construct validity was evaluated by comparing the OIDP scores with the objectively assessed oral status. It was hypothesized that a modest correlation existed between the OIDP score and the presence of removable prostheses. Finally, we reviewed the language of the survey items and the format of the questionnaire based on suggestions made by the interviewer and respondents.

Prior to conducting the interviews, we explained the survey to the subjects and informed them that their participation was voluntary. Information that might identify individuals was kept confidential, and responses were analyzed in such a way that they could not be traced back to an individual respondent.

\section{Results}

In 2004, we used the preliminary Japanese version of the OIDP scale in a pilot study that involved 47 residents (19 males and 28 females) of Kyoto and Naze, Japan, who participated in municipal health checkups. The average age of the subjects was 69 years (range, 40-105 years), with $13 \%$ of the participants in their $40 \mathrm{~s}, 17 \%$ in their $50 \mathrm{~s}, 32 \%$ in their 60 s, $15 \%$ in their 70 s, and $23 \%$ over the age of 80 years.

Forty-five percent of the participants responded that oral health problems had affected their daily life in some way over the past 6 months. The proportion of participants reporting problems increased with age among participants between the ages of 50 and 80 years, whereas this trend decreased among participants over the age of 80 years. Fifty-seven percent of removable denture wearers and $35 \%$ of individuals without dentures indicated that oral discomfort had affected their lives. In addition, denture wearers had significantly higher OIDP scores (6.5 versus $0.7)$ in a covariance analysis with age and sex as adjustment factors $(P<0.05)$.

In our item analysis, the missing value rate was $0 \%$ and no ambiguous responses were recorded. More than 16\% replied that they 'had trouble caused by an oral health problem' in the 'eating', 'mental stability', 'conversation', and 'laughing' items (Table 1). Trouble regarding 'cleaning teeth or dentures' and 'smiling' were unlikely to have 
impacts on daily performance. The mean $( \pm$ SD) OIDP score was $3.5 \pm 7.1$ (range, $0-38$ ). Furthermore, among those who reported that they had experienced discomfort, $82 \%$ replied that 'these discomforts affected my daily life'. An examination of internal consistency and reliability revealed that the corrected item-total correlation coefficients for all items, except 'teeth cleaning' and 'sleep', satisfied the respective criteria (Table 2). The Cronbach's alpha coefficient for our reliability analysis was 0.772 .

\section{Discussion}

We developed a Japanese version of the OIDP for use in an interview setting. Many interview-based surveys involved elderly subjects, and numerous studies have applied the interview version of the OIDP in the elderly (27-29). Thus, in the present pilot study, we primarily included elderly subjects.
As the subjects did not appear to have any trouble understanding the language of the questions or the options, we decided to use a Japanese translation that was as close as possible to the English original. No changes were made in the scoring or the order of the items. While conducting a pilot study, we included multiple-choice cards for the subjects and an explanatory document for the interviewers, together with instruments, as we felt that these were important for the study to proceed smoothly. Multiplechoice cards that contained the same content as the questionnaire were used to elicit an answer to each question.

A few items showed strongly skewed responses in the pilot study. We did not find specific reasons related to the subjects' interpretations of the items. Most of our subjects were recruited from an urban area. Consequently, locality of residence might have affected the response patterns, although the sample size was not enough for confirmation

Table 1 Prevalence of oral health problems and oral impacts on daily performances

\begin{tabular}{|c|c|c|c|c|}
\hline \multirow[t]{2}{*}{ Performance } & \multicolumn{2}{|c|}{$\begin{array}{l}\text { Having trouble because of problems with } \\
\text { mouth or teeth or removable dentures }\end{array}$} & \multicolumn{2}{|c|}{$\begin{array}{l}\text { Having impact on daily performances } \\
\text { because of these troubles }\end{array}$} \\
\hline & No & $\%$ & No & $\%$ \\
\hline Eating food & 13 & 27.7 & 12 & 25.5 \\
\hline Speaking & 8 & 17.0 & 7 & 14.9 \\
\hline Cleaning teeth or dentures & 6 & 12.8 & 3 & 6.4 \\
\hline Doing light physical activities & 2 & 4.3 & 1 & 2.1 \\
\hline Going out & 1 & 2.1 & 1 & 2.1 \\
\hline Sleeping & 2 & 4.3 & 2 & 4.3 \\
\hline Relaxing & 5 & 10.6 & 4 & 8.5 \\
\hline Smiling, laughing without embarrassment & 8 & 17.0 & 5 & 10.6 \\
\hline Emotional state; becoming easily upset & 9 & 19.1 & 9 & 19.1 \\
\hline Enjoying contact with people & 2 & 4.3 & 2 & 4.3 \\
\hline
\end{tabular}

Table 2 Item-scale correlations for the OIDP items

\begin{tabular}{|c|c|c|c|c|c|c|c|c|c|c|}
\hline $\begin{array}{l}\text { OIDP } \\
\text { item }\end{array}$ & $\begin{array}{l}\text { Eating } \\
\text { food }\end{array}$ & Speaking & $\begin{array}{l}\text { Cleaning } \\
\text { teeth or } \\
\text { dentures }\end{array}$ & $\begin{array}{c}\text { Doing } \\
\text { light } \\
\text { physical } \\
\text { activities }\end{array}$ & $\begin{array}{l}\text { Going } \\
\text { out }\end{array}$ & Sleeping & Relaxing & $\begin{array}{c}\text { Smiling, } \\
\text { laughing } \\
\text { without } \\
\text { embarrassment }\end{array}$ & $\begin{array}{l}\text { Emotional } \\
\text { state; } \\
\text { becoming } \\
\text { easily upset }\end{array}$ & $\begin{array}{c}\text { Enjoying } \\
\text { contact } \\
\text { with } \\
\text { people }\end{array}$ \\
\hline $\begin{array}{l}\text { Item-scale } \\
\text { correlation }\end{array}$ & 0.893 & 0.636 & 0.175 & 0.729 & 0.729 & 0.093 & 0.649 & 0.742 & 0.754 & 0.666 \\
\hline
\end{tabular}

Cronbach's $\alpha=0.772$ 
of the findings. A previous study using another language version of the OIDP has also reported skewed responses to some items (14). Analysis of the relationship between response patterns and subjects' characteristics could be important under various settings. The items 'teeth cleaning' and 'sleep' indicated lower corrected item-total correlations than the minimum recommended level of 0.20 (30). It may be that these items were conceptually different from the others and unlikely to become synchronized; however, further assessment should be performed to confirm this conclusion. Usually, internal consistency is considered to be sufficient when the alpha coefficient is greater than 0.7 (25), a condition that was met here. For the association between OIDP scores and the presence of removable prostheses, the hypothesis relating to construct validity was also met. The test-retest reliability was not evaluated in this study. Further assessment is needed, as well as a validation study with a larger sample.

We created a Japanese version of the OIDP scale following this analysis. A native English-speaking bilingual translator, who was not involved in the initial English-toJapanese conversion, then translated the Japanese version back to the original language. The back translation was then approved by the original author. The author also provided comments regarding the wordings and interpretations of some items. For example, the back translation contained the phrase 'At what rate,' while in the original text, the phrase was 'How often.' This was changed to 'At what rate [frequency]' to follow the original more closely, although this constitutes a linguistic difference between Japanese and English.

We also considered the phrase 'find it difficult to attend to your oral care (brushing your teeth or taking care of your dentures)' in the reverse translation of 'cleaning teeth or dentures'. The interpretation given in parentheses was considered to be necessary because the item refers to oral hygiene and the words 'oral care' might cause misunderstanding. After discussion, this sentence was revised to 'find it difficult to clean your mouth (for example, brushing teeth)'. The final version was revised according to the original author's comments and then reconfirmed by the author.

The following three features are characteristic of the OIDP scale. First, the scale evaluates not only the existence and degree of oral health problems but also the extent to which such problems affect one's daily life. In our pilot study, we came across patients with oral health problems who did not think that these problems affected their daily life, which represented a new perspective on the evaluation of oral health-related QOL. Second, sleep and physical activity were included among the 10 items. As other oral health-related QOL scales emphasize oral functions as targets for physical evaluation, this scale is potentially useful for assessing QOL evaluation of the impact of oral health on the activities of daily life, especially for fragile elderly subjects. The third characteristic of the OIDP scale is that it includes evaluations of the frequency and duration of oral discomfort. The GOHAI, for example, contains questions about the frequency of discomfort over the past 3 months, although cases may exist in which this greatly lowers the QOL score if the discomfort occurs only once and continues over a certain period of time. The OIDP has been carefully designed so that it can deal with both parameters (i.e., the frequency and duration of oral discomfort), and is useful for evaluating effects other than those that occur daily.

As for the previous studies that used the interview version of the OIDP, Sheiham et al. (28) conducted a study on a group of individuals who participated in the oral health component of the National Diet and Nutrition Survey, and compared these results with those of their dietary study. They found that the oral status frequently affected the QOL of older people and, in particular, their ability to eat common types of food. In another study, Tsakos et al. (29) showed a strong and consistent relationship between the OIDP scores and the number of occluding pairs of natural teeth in dentate subjects, and the presence of denture adaptation and retention problems in edentate subjects. These results demonstrate that oral health problems affect daily life, and we hope that similar studies using the National Survey data will be conducted in Japan in the near future.

With the original author's permission, the Japanese version of the OIDP for use in interview was completed. Further assessments and validations of this scale are needed in a study with a larger sample size.

\section{Acknowledgments}

We extend our deepest thanks to Dr. Georgios Tsakos of the Royal Free and University College London Medical School for his valuable advice in developing the Japanese version of the OIDP and critically reviewing the manuscript. We would also like to thank Dr. Yoichi Hino of the Kagoshima University Graduate School of Medical and Dental Sciences, Dr. Takayo Matsumura of the Kyoto University Graduate School of Medicine, and Ms. Ikuko Tani for their help in conducting the pilot study.

\section{References}

1. Raphael D, Renwick R, Brown I, Rootman I (1996) Quality of life indicators and health: current status and emerging conceptions. Soc Indic Res 39, 65- 
88

2. Locker $\mathrm{D}$ (1988) Measuring oral health: a conceptual framework. Community Dent Health 5, 3-18

3. Slade GD, Spencer AJ (1994) Development and evaluation of the Oral Health Impact Profile. Community Dent Health 11, 3-11

4. Atchison KA, Dolan TA (1990) Development of the geriatric oral health assessment index. J Dent Educ 54, 680-687

5. Adulyanon S, Vourapukjaru J, Sheiham A (1996) Oral impacts affecting daily performance in a low dental disease Thai population. Community Dent Oral Epidemiol 24, 385-389

6. Astrøm AN, Haugejorden O, Skaret E, Trovik TA, Klock KS (2006) Oral Impacts on Daily Performance in Norwegian adults: the influence of age, number of missing teeth, and socio-demographic factors. Eur J Oral Sci 114, 115-121

7. Mason J, Pearce MS, Walls AW, Parker L, Steele JG (2006) How do factors at different stages of the lifecourse contribute to oral-health-related quality of life in middle age for men and women? J Dent Res 85, 257-261

8. Wong MC, McMillan AS (2005) Tooth loss, denture wearing and oral health-related quality of life in elderly Chinese people. Community Dent Health 22, 156-161

9. Ikebe K, Watkins CA, Ettinger RL, Sajima H, Nokubi T (2004) Application of short-form oral health impact profile on elderly Japanese. Gerodontology 21, 167-176

10. Ide R, Yamamoto R, Mizoue T (2006) The Japanese version of the Oral Health Impact Profile (OHIP) validation among young and middle-aged adults. Community Dent Health 23, 158-163

11. Naito M, Suzukamo Y, Nakayama T, Hamajima N, Fukuhara S (2006) Linguistic adaptation and validation of the General Oral Health Assessment Index (GOHAI) in an elderly Japanese population. J Public Health Dent 66, 273-275

12. Fujii Y, Yamakawa E, Naito M (2006) Oral healthrelated QOL and frequent (long-term) attendance in oral health check-ups at the workforce. Koku Eisei Gakkai Zasshi 56, 509 (in Japanese) (abstract)

13. World Health Organization (1980) International classification of impairments, disabilities and handicaps. WHO, Geneva, 7-19

14. Dorri M, Sheiham A, Tsakos G (2007) Validation a Persian version of the OIDP index. BMC Oral Health 7, 2

15. Gherunpong S, Tsakos G, Sheiham A (2004)
Developing and evaluating an oral health-related quality of life index for children: the CHILD-OIDP. Community Dent Health 21, 161-169

16. Tubert-Jeannin S, Pegon-Machat E, GremeauRichard C, Lecuyer MM, Tsakos G (2005) Validation of a French version of the Child-OIDP index. Eur J Oral Sci 113, 355-362

17. Soe KK, Gelbier S, Robinson PG (2004) Reliability and validity of two oral health related quality of life measures in Myanmar adolescents. Community Dent Health 21, 306-311

18. Astrøm AN, Okullo I (2003) Validity and reliability of the Oral Impacts on Daily Performance (OIDP) frequency scale: a cross-sectional study of adolescents in Uganda. BMC Oral Health 3, 5

19. Masalu JR, Astrøm AN (2003) Applicability of an abbreviated version of the Oral Impacts on Daily Performances (OIDP) scale for use among Tanzanian students. Community Dent Oral Epidemiol 31, 714

20. Gherunpong S, Sheiham A, Tsakos G (2006) A socio dental approach to assessing children's oral health needs: integrating an oral health-related quality of life (OHRQoL) measure into oral health service planning. Bull World Health Organ 84, 3642

21. Gherunpong S, Tsakos G, Sheiham A (2006) A sociodental approach to assessing dental needs of children: concept and models. Int J Paediatr Dent $16,81-88$

22. McMillan AS, Leung KC, Pow EH, Wong MC, Li LS, Allen PF (2005) Oral health-related quality of life of stroke survivors on discharge from hospital after rehabilitation. J Oral Rehabil 32, 495-503

23. Trabal J, Leyes P, Forga MT, Hervás S (2006) Quality of life, dietary intake and nutritional status assessment in hospital admitted cancer patients. Nutr Hosp 21, 505-510

24. Gherunpong S, Tsakos G, Sheiham A (2006) A socio-dental approach to assessing children's orthodontic needs. Eur J Orthod 28, 393-399

25. Acqudro C, Jambon B, Ellis D, Marquis P (1996) Language and translations issues. In Quality of life and pharmacoeconomics in clinical trials, 2nd ed, Spilker B ed, Lippincott Williams \& Wilkins, Philadelphia, 575-585

26. Cronbach LJ, Warrington WG (1951) Time-limit tests: estimating their reliability and degree of speeding. Pschometrika 16, 167-188

27. Tsakos G, Marcenes W, Sheiham A (2001) Evaluation of a modified version of the index of Oral 
Impacts On Daily Performances (OIDP) in elderly populations in two European countries. Gerodontology 18, 121-130

28. Sheiham A, Steele JG, Marcenes W, Tsakos G, Finch S, Walls AW (2001) Prevalence of impacts of dental and oral disorders and their effects on eating among older people: a national survey in Great Britain. Community Dent Oral Epidemiol 29, 195-203
29. Tsakos G, Steele JG, Marcenes W, Walls AW, Sheiham A (2006) Clinical correlates of oral healthrelated quality of life: evidence from a national sample of British older people. Eur J Oral Sci 114, 391-395

30. Kline P (1986) A handbook of test construction: introduction to psychometric design. Methuen, London, 133-149. 